\title{
UMA FORMAÇÃO PEDAGÓGICO-REFLEXIVA EM PSICOLOGIA: ANÁLISE DE DIÁRIOS DE APRENDIZAGEM
}

\author{
A pedagogical-reflexive experience at a Psychology course: analysis of learning logs \\ Una formación pedagógica-reflexiva en Psicología: análisis de diarios de aprendizaje
}

\author{
JULIANA CRESPO LOPES \\ Francielly de Oliveira MÜLler Lima \\ Sandra Ferraz de Castilho Dourado Freire \\ Lucia Helena Cavasin Zabotto Pulino
}

\begin{abstract}
Resumo: O presente artigo buscou, através da análise de diários de aprendizagem, discutir a respeito das possibilidades que uma formação universitária em psicologia que seja acolhedora e promotora de reflexões pode ter na formação de estudantes de psicologia. Foram analisados treze diários redigidos por estudantes do sexto semestre de um curso de graduação em Psicologia matriculados em uma disciplina relacionada à Abordagem Centrada na Pessoa de um Centro Universitário do Centro-Oeste brasileiro. Os diários foram escritos tendo como base a concepção de Versão de Sentido, com uma escrita livre após as aulas. Foi utilizada a Análise Temática e, a partir dela emergiram seis temas que demonstraram a importância da construção de um espaço acadêmico dialógico que promova as condições facilitadoras para o desenvolvimento pessoal e profissional.

Palavras-chave: Formação em Psicologia; Diário de Aprendizagem; Processos de Reflexão; Condições Facilitadoras para Aprendizagem; Abordagem Centrada na Pessoa.
\end{abstract}

\begin{abstract}
The present article aimed, through the analysis of learning diaries, to discuss about the possibilities that a psychology university degree which promotes reflection and shelters students' thoughts and emotions can have in the training of psychology students. Were analyzed thirteen learning logs written by students of the sixth semester of an undergraduate degree course in Psychology enrolled in a discipline related to the Person Centered Approach.The logs were written based on the Sense's Version, after each class, with indication of free writing. Thematic Analysis was used, and from it six themes emerged that demonstrated the importance of building an academic context that promotes the facilitating conditions for personal and professional development.

Keywords: Psychology Degree; Learning Log; Reflection Process; Core Conditions to Facilitate Learning, Person Centered Approach.

Resumen: El presente artículo buscó, a través del análisis de diarios de aprendizaje, discutir acerca de las posibilidades que una formación universitaria en psicología que sea acogedora y promotora de reflexiones puede tener en la formación de estudiantes de psicología. Se analizaron trece diarios redactados por estudiantes del sexto semestre de un curso de graduación en Psicología matriculados en una disciplina relacionada al Enfoque Centrado en la Persona. Los diarios fueron escritos teniendo como base la concepción de Versión de Sentido, con una escritura libre después de las clases. Se utilizó el Análisis Temático y, a partir de ella surgieron seis temas que demostraron la importancia de la construcción de un espacio académico dialógico que promueve las condiciones facilitadoras para el desarrollo personal y profesional. Palabras-clave: Formación en Psicología, Diario de Aprendizaje, Procesos de Reflexión; Condiciones para el Aprendizaje; Enfoque Centrado en la Persona.
\end{abstract}

\section{Introdução}

Foi interessante discutir mais sobre o propósito do diário: treinar o olhar para nós mesmos e reconhecer nossos sentimentos. É como fazer um exercício pessoal. (DGS)

Estudantes de psicologia podem se beneficiar de espaços promotores de reflexão, sejam oriundos de processos internos ou acadêmicos, para o desenvolvimento pessoal, acadêmico e profissional. O reconhecimento do diário como ferramenta reflexiva sobre a própria formação vem, na declaração de DGS, primeiramente, em uma ação intencional de voltar a atenção aos aspectos afetivos. O uso de termos como treinar, reconhecer, fazer um exercício denotam a indicação de uma ação deliberada ao autoconhecimento, este dado pelas expressões como nós mesmos, nossos sentimentos e exercício pessoal. Partindo dessa visão, apresentamos e analisamos neste artigo algumas reflexões produzidas em diários de estudantes de Psicologia de uma universidade particular brasileira.

Diários de aprendizagem têm como funções o desenvolvimento de pensamento e prática reflexivos 
e críticos; aumentar o envolvimento ativo de estudantes; colaborar no desenvolvimento pessoal, autoempoderamento e mudança de comportamentos; e como espaço de autoexpressão (Moon, 2006). Enfatizando o autoempoderamento, tem-se que a reflexão contribui para um processo de construção de conhecimentos ao invés de uma regulação externa (Freire \& Duarte, 2016). Dessa forma, é importante que exista um estímulo significativo ao desenvolvimento de habilidades de autorregulação e de aprendizagem em estudantes no início de seus percursos na Educação Superior (Räisänen, Postareff \& Lindblom-Ylänne, 2016).

A escrita de diários a respeito de conteúdos estudados desencadeia uma mudança na experiência própria da(o) estudante a partir do processo de reflexão (Moon, 2006). Considerando que existem várias compreensões a respeito do que define o processo de reflexão (Rodgers, 2002), desejamos situar a prática promovida pela escrita do diário como um pensamento reflexivo (Dewey, 1933) ao mesmo tempo em que se caracteriza em um campo subjetivo da Versão de Sentido (Amatuzzi, 2001).

O pensamento reflexivo incita a investigação e tem por objetivo uma conclusão, extrapolando um simples raciocínio sequencial (Dewey, 1933). No caso dos diários, objeto deste estudo, sua escrita foi proposta em uma disciplina sobre práticas psicoterápicas a partir da Abordagem Centrada na Pessoa. Dentro dessa perspectiva, foi sugerida uma escrita onde a investigação teria um caráter pessoal, sem estar presa a moldes acadêmicos, pautada no que Amatuzzi (2001, p. 84) entende ser a Versão de Sentido (VS): uma "fala, o mais autêntica possível, que toma como referência intencional um encontro vivido, pronunciada logo após sua ocorrência". Vieira, Bezerra, Pinheiro e Branco (2018) fizeram uso da VS em uma situação de supervisão de estágio em psicologia e afirmam que tal instrumento tem sido uma prática que proporciona ao estudante entrar em contato com os sentidos produzidos na relação com os clientes da clínica psicológica. Similarmente, na prática pedagógica aqui adotada, ao se trabalhar com conteúdos a respeito de posturas e habilidades interpessoais necessárias em um trabalho psicoterápico, viu-se na escrita dos diários pautada na VS, a abertura de um espaço para o pensamento reflexivo acerca de estudantes, suas posturas, percepções e considerações atuais e referentes ao futuro profissional.

\section{Processos Reflexivos Relacionados à ACP e ao Dialogismo na Formação de Psicólogas(os)}

$\mathrm{O}$ curso de psicologia na graduação extrapola o ensino de conceitos, teorias e ferramentas psicológicas para estudantes. Por trabalhar com a subjetividade humana, muitos dos conteúdos emocionais dos próprios universitários serão mobilizados ao longo dessa formação. Estes sujeitos entram em contato com sua própria subjetividade ao serem apresentados a teorias psicológicas e não raro vivenciam sofrimento psíquico no mesmo momento em que estão aprendendo teoricamente sobre o mesmo (Bock, 2015). É como se, ao longo de sua formação, aprendessem teoricamente sobre um conteúdo ao mesmo tempo em que o vivenciam de forma diversificada ao longo da trajetória de vida

É imensamente importante que o futuro psicólogo desenvolva em si mesmo a habilidade de reconhecer seus próprios sentimentos, seus próprios medos e limitações. Para Rogers (2001a) o próprio terapeuta precisaria experimentar em si um processo de mudança a fim de efetivamente poder ajudar seu cliente a mergulhar em seu próprio processo, superando seus medos e inseguranças. Esse mergulho na experiência de mudança, facilitado no caso desta pesquisa pela construção dos diários de aprendizagem, oferece aos sujeitos a possibilidade de adquirir outras habilidades absolutamente importantes para um facilitador na relação terapêutica: autoconhecimento, autoaceitação e honestidade consigo mesmo (Tambara \& Freire, 2007).

Um desafio na formação de psicoterapeutas é que a genuidade da experiência de acolhimento do outro seja vivenciada para além da técnica e que exista uma elaboração consistente do vivido garantindo que a relação se torne produtiva (Vieira et al., 2018). Ao olhar para si e reconhecer suas vivências internas sem julgamentos ou resistências, podendo registrá-las através de palavras escritas, a pessoa tem a chance de se aproximar de forma legítima e corajosa de si mesma, desenvolvendo a habilidade de centrar-se em si para, posteriormente, ser capaz de centrar-se no outro (Rogers 2001b). Através dessa imersão em si mesma, com um olhar sem julgamentos para suas experiências vividas, o sujeito apreende atitudes de autocuidado, autoempatia, autoaceitação e autenticidade. Observar e vivenciar a sua própria potência desenvolve nos futuros terapeutas a confiança nessa capacidade intrínseca a todo organismo vivo, que é a Tendência Atualizante.

A Tendência Atualizante é o impulso em direção à vida e a habilidade do organismo de imporse, ainda que em um ambiente hostil, e não apenas manter-se, mas adaptar-se, desenvolve-se e tornar-se ele mesmo. Dessa forma, entende-se o ser humano como um organismo que está sempre motivado, em busca de algo. É essa confiança na existência de uma fonte central de energia no organismo humano que leva à compreensão de que há, intrinsecamente, uma tendência à consecução, à realização. Não apenas à manutenção, mas também ao desenvolvimento do organismo (Rogers, 2001b).

Para que se crie um ambiente facilitador do desenvolvimento, tanto pessoal quanto, especificamente, na formação de psicólogos, é necessário que o indivíduo possa vivenciar um 
relacionamento humano caloroso e verdadeiro, onde um significado pessoal seja experienciado e um clima de segurança emocional seja oferecido. Para que esse clima seja construído, é imprescindível que a pessoa que se propõe a ser o facilitador desse processo (no caso da educação, a/o docente) desenvolva atitudes que irão promover uma relação de confiança e segurança onde esse sujeito possa sentir-se aceito e considerado exatamente como é, com todo o seu potencial. Essa relação cria o ambiente propício para que o potencial, que já está presente no sujeito, se manifeste e promova o seu crescimento, através de suas relações com o outro e com o meio (Rogers 2001a).

Relações dialógicas possibilitam práticas pedagógicas onde os sujeitos - docentes e discentes - podem relacionar-se não mais a partir de uma hierarquia de saberes e sim de forma autônoma e horizontal. Essa postura possibilita que ambos reconstruam dialogicamente seu self na relação com os conhecimentos e sentimentos vivenciados (Ressurreição \& Sampaio, 2017). É a interação na aula e o diálogo que possibilitam a construção conjunta do saber, sendo interessante que docentes caminhem ao lado de estudantes pelo processo de conhecer o mundo. É esta relação dialógica que auxilia e permite que as possibilidades do sujeito sejam conhecidas, oportunizando que os novos conhecimentos adquiridos sejam considerados como catalisadores que atuam como recursos simbólicos para o amadurecimento e aquisição de competências dos jovens estudantes (Tacca, 2015).

Este estudo buscou investigar as manifestações reflexivas e as possibilidades de desenvolvimento pessoal e acadêmico de estudantes de psicologia através da análise de diários de aprendizagem construídos, no formato de Versão de Sentido (Amatuzzi, 2001), após cada aula de uma disciplina sobre a Abordagem Centrada na Pessoa, por estudantes de um curso de Psicologia.

\section{Metodologia}

Trata-se de uma pesquisa qualitativa da qual participaram treze estudantes de graduação de Psicologia de uma Instituição de ensino superior, entre os quais dez mulheres e três homens, de 20 a 55 anos, matriculados, à época, no $6^{\circ}$ semestre do curso. A pesquisa foi realizada no contexto de em uma disciplina ministrada por uma das autoras, sobre a prática clínica na Abordagem Centrada na Pessoa. A autorização foi fornecida em Termo de Consentimento Livre e Esclarecido e a análise foi realizada após o término da disciplina, não tendo influenciado a atribuição de notas. A pesquisa foi autorizada pelo Comitê de Ética em Pesquisa em Ciências Humanas e Sociais da Universidade de Brasília, pela Plataforma Brasil, com Parecer Consubstanciado número 3.527.081.

Os participantes construíram Versões de Sentido, que é um documento de autorrelato livre, que não tem a pretensão de ser um registro objetivo do que aconteceu, mas sim uma reação viva a isso (Amatuzzi, 2001). Este é um recurso que trata da descrição de breves relatos da experiência imediata do estudante. A Versão de Sentido possibilita um olhar para si e a autorreflexão, sendo um registro verbal feito, neste caso, por escrito imediatamente após a experiência da aula. Os estudantes receberam a instrução de descreverem suas percepções sobre si naquele momento, incluindo sentimentos e sensações como um convite a olharem para si. A Versão de Sentido é uma versão do sentido vivido de um encontro, através do sentido vivido logo depois e pode auxiliar no aprimoramento e na transformação pessoal, levando os estudantes ao protagonismo de sua formação pessoal e, consequentemente, profissional. "Como produção, a Versão de Sentido é a fala, o mais autêntica possível, que toma como referência intencional um encontro vivido, pronunciada logo após sua ocorrência..." (Amatuzzi, 2001, p. 84). A Versão de Sentido pode, ainda ser considerada um produto, por ser um texto expressivo da experiência imediata, escrito por iniciativa da própria pessoa, ou solicitado por um interlocutor. Segundo Vieira, Bezerra, Pinheiro e Branco (2018), esta é uma maneira de se aproximar da experiência que mobiliza a experiência genuína.

Os registros se referiam a processos vividos durante a disciplina, bem como no espaço temporal no qual a mesma estava inserida. Foram chamados de Diários de Bordo, a fim de caracterizarmos como processuais as transformações percebidas pelos sujeitos ao longo desta construção. Os diários foram selecionados de acordo com os seguintes critérios de inclusão: (a) amostragem que incluísse mulheres e homens, apesar da predominância de participantes do gênero feminino; (b) narrativas analíticas e reflexivas, caracterizadas por posicionamento interpretativo dos eventos e/ou episódios relatados, exploração do sentido; (c) diários com prevalência de elementos interpretativos-analíticos.

Foi empregada a Análise Temática (Norton, 2008) para a definição das categorias de análise. Os indicadores narrativos considerados foram: (a) relatos de situações vividas em aula com posterior reflexão (b) uso de verbos - no presente ou passado - indicando afeto: percebo, penso, sinto, amo, gosto, acho, desejo, quero; bem como expressões emotivas, como: feliz, alegre, triste, pensativa, chateada, incrível, legal, desanimada, interessada; (c) indicação da qualidade do afeto em relação à outra pessoa e aos episódios; (d) usos da palavra mudança e/ou transformação. Dessa forma, foram categorizados os registros utilizando cores em que se mapearam, primeiramente, os indicadores reflexivos. Depois, foram construídos os diferentes temas de acordo com o conteúdo específico de cada afirmativa reflexiva. E, por fim, foram construídos temas a partir da delimitação desses conteúdos específicos. 


\section{Resultados}

No processo de análise encontramos que as reflexões discentes se relacionavam a cinco temas, apresentados a seguir juntamente com a frequência com que foram mencionados nos diários: Mudanças nos estudos e atitudes nas aulas (26); Mudanças na vida (24); Desenvolvimento de habilidades interpessoais (18); Relação entre professora e estudantes (15); e Futuro enquanto profissional da psicologia (08).

A seguir discutiremos pormenorizadamente cada um dos temas que emergiram durante a análise.

\section{Mudancas nos estudos e atitudes nas aulas}

Temas relacionados a mudanças nos estudos e em atitudes nas aulas apareceram em onze dos treze diários, com 26 ocorrências. Algumas reflexões versaram a respeito de maior motivação no envolvimento com as aulas, fosse a respeito de continuar no curso e frequentar as aulas mesmo em dias de cansaço, fosse a participação mais ativa nas aulas e mais dedicação à leitura.

Hoje eu me senti muito concentrada na aula. De verdade. Não me distraí, não tive vontade de pegar o celular em nenhum momento, não me perdi em outros pensamentos, estive totalmente presente. Fiquei feliz! (GCB)

A vivência de um espaço onde é promovida a autodescoberta mostra-se facilitadora do processo de engajamento de estudantes com a sua própria formação. Rogers (1983) explica que é possível criar um clima facilitador da aprendizagem a partir de uma atmosfera de autenticidade, interesse a atenção. $\mathrm{O}$ autor adiciona ao fato, ainda, que inicialmente o espaço é criado pela figura da(o) facilitador(a) e, ao longo do tempo, estudantes passam a fomentá-lo. É possível perceber que o interesse e comprometimento de estudantes com a aula, além de sua satisfação ao se perceber nesse lugar, está diretamente ligado à modificação de seu comportamento enquanto estudante. Evidencia-se, aqui, o movimento da automotivação à aprendizagem e à construção pessoal, quando o clima interpessoal é acolhedor e convidativo para isso (Rogers, 2001a).

Encontramos registros de estudantes refletindo sobre não conseguirem aproveitar as aulas para as quais não se preparavam previamente, inclusive tendo a iniciativa de ler os textos referentes às aulas seguintes após reflexão no diário:

Parei para pensar como eu estava distraída ultimamente nas aulas de quase todas as matérias. (...) [na semana seguinte] Resolvi ler o texto para a aula. Foi aí que a mágica aconteceu: aquele texto mexeu comigo. Tirou muitas dúvidas que eu ainda tinha sobre a ACP e trouxe várias novas. Fui para a aula feliz naquele dia, pois, pela primeira vez, teria sentido estar ali. (...) Saí de lá entendendo tudo e animada para ler o próximo texto e sentir aquilo de novo. (MSGS)

O interesse de estudantes em conteúdos que se relacionam diretamente com suas vivências influencia significativamente seus próprios comportamentos. Rogers (2001a) defende que, quando estudantes universitários encaram sua formação como uma experiência que podem utilizar para resolver questões da sua existência, há um sentimento de alívio e progresso nos mesmos. Também é interessante destacar que há aí o desenvolvimento da autodisciplina, uma habilidade necessária para que estudantes atinjam suas metas sem a necessidade de uma disciplina externa (Rogers, 1983).

É notória a presença da motivação para a aprendizagem quando estudantes experimentam protagonizar seu processo de construção de conhecimento, sejaassumindouma postura diferente, como ler o texto e preparar-se antecipadamente para as discussões em sala, seja pela possibilidade de utilizar os conteúdos trabalhados como catalizadores de mudanças pessoais significativas. Tal postura nas relações de aprendizagem pode promover profissionais capazes de refletir, criar, questionar a si mesmo e desejosos de encontrar realização na sua prática profissional (Flôr, 2016).

Estudantes identificaram comportamentos desatentos no início do semestre, percebendose mais atentos a partir da identificação com os conteúdos emergentes:

No começo da aula eu me senti um pouco distante, pois estava preocupada com a prova que teria no segundo horário. Entretanto, aceitei que tudo que eu poderia saber para a prova eu já sabia, porque eu tinha estudado tanto quanto eu poderia. Além disso, o conteúdo da aula foi ficando mais atrativo para mim, porque os assuntos sobre o auto aprimoramento do indivíduo sempre me interessam. (BSG)

Está evidenciada nesse trecho a aprendizagem significativa (Rogers, 2001a), onde há um desenvolvimento integral do sujeito, oportunizando que ele desenvolva coragem e responsabilidade de construir suas realidades. A percepção de si, retratada pela aluna, demonstra abertura à sua própria experiência imediata, com a possibilidade de acolhêla e vivenciá-la sem defesas, permitindo-se entregarse a essa experiência e modificar-se (Flôr, 2016).

Outro ponto de destaque é o diário servindo como ferramenta dialógica, promovendo a continuidade da reflexão e o encontro de respostas e 
novas possibilidades de pensamento:

Depois pensei no que tinha dito e veio o seguinte questionamento: "como fazer isso acontecer?" Acredito que se alguém me perguntasse isso, não saberia responder na hora, surgiu uma certa frustração ao pensar "será que a viagem que embarquei foi apenas de ida?" Ao escrever esse texto consegui a "passagem de volta". (MVN)

A fala - e aí podemos incluir a escrita reflexiva, como um exercício de diálogo consigo - é uma ferramenta que desperta e promove descobertas relacionadas a conteúdos eminentemente pessoais (Amatuzzi, 1989). A palavra ou expressão verbal estão presentes na escrita, e, como na fala, esse conteúdo descoberto percebido na palavra é denominado de sentimento e de experiência. É uma vivência pré-verbal, mas descoberta ou despertada pelo verbal.

Por fim, são ressaltadas as práticas pedagógicas que, de alguma forma, se aproximavam mais de vivências práticas, como a observação de atendimentos e a discussão de exemplos em sala de aula:

Percebi que quando a aula gira mais em torno de exemplos práticos, de conversas com a turma sobre fatos reais de vivências pessoais de cada um é mais fácil de assimilar a teoria. (GCB)

As instituições de educação - seja ela básica ou superior - têm buscado implementar inovações metodológicas e tecnológicas buscando atender demandas geradas pelas transformações nas sociedades, pessoas e mercado. Algumas mudanças se configuram apenas como atualizações de ferramentas, outras, porém são fruto de alterações metodológicas e posturais e colaboram para processos de construção de conhecimentos mais significativos. Como exemplos dessas últimas, temos ampla variedade de métodos de ensino e aprendizagem, como estudo centrado em estudantes, PBL, educação experiencial, aprendizagem auto direcionada, educação humanística, aprendizado através da reflexão e aprendizagem ativa, todos considerados por Heim (2012) como aplicações pedagógicas da Abordagem Centrada na Pessoa.

\section{Mudanças na vida}

O segundo tópico, também abordado por onze estudantes, apareceu em 24 registros e se refere a mudanças na vida pessoal de estudantes. Podemos encontrar modificações nas relações com familiares, amigos e companheiros(as):

Me senti emocionada e grata por estar fazendo esse curso. Me fez refletir comportamentos que venho tendo e que talvez não estejam sendo os melhores para ajudar alguém que eu amo. (LRC)
Rogers (2001b) defende que pessoas envolvidas em um clima centrado na pessoa encontram maior aceitação de seus próprios "eus" peculiares e tendem a explorar suas diferenças, tornando-se mais abertas também ao outro. Esse clima proporciona maior reconhecimento do valor da individualidade, o que é estendido à aceitação das singularidades do outro. Sentir-se aceito pelo outro é um fator facilitador do processo de autoaceitação. Da mesma maneira, o processo de autoaceitação é também facilitador do desenvolvimento da capacidade de aceitar o outro da maneira que é. Dessa forma, em um ciclo que se retroalimenta, a pessoa torna-se mais capaz de ser congruente consigo e empática com o outro Rogers (2001a).

É possível observar nos registros pessoais dos diários que os conteúdos abordados em sala repercutem e tocam em seus conteúdos emocionais pessoais, trazendo ecos e mudanças internas a partir do sentido dado ao conteúdo exposto pela professora. Construir no espaço acadêmico um clima de segurança emocional onde estudantes possam transitar entre seus conteúdos internos e simbolizálos pode favorecer o desenvolvimento de um princípio fundamental para a formação do psicólogo: desenvolver um olhar generoso e respeitoso para si, promovendo autocuidado, entendido aqui como o ato de atentar-se às próprias demandas, respeitandose em seu processo não apenas de formação, mas em sua vida (Dourado, Quirino, Lima \& Melo, 2016). Dessa forma, o processo de autoaceitação será facilitado, levando os sujeitos a tornarem-se mais congruentes e autênticos, haja vista a ausência de ameaças às suas experiências internas que poderão ser validadas pelo outro:

Estou parando para pensar em como me sinto em relação a várias coisas, e percebi que quase nunca faço isso. (LM)

Acho que eu me interesso por esses assuntos porque eu sinto como se eu vivesse essas evoluções. Analisando em retrospectiva, eu vejo uma transformação na forma como eu me vejo, na maneira como eu encaro as situações e como eu tomo as decisões. Essa aula sobre as fases terapêuticas foi quase uma leitura do meu próprio eu e saber que acontece comigo é o que me faz acreditar que pode acontecer com qualquer pessoa e destaca ainda mais a importância da aceitação da pessoa como ela é. (BSG)

Acho que essa sempre foi minha ressalva com relação a ACP e as demais abordagens não diretivas: se eu não acredito que a minha tendência atualizante vai ser suficiente para guiar o meu caminho em direção ao crescimento, à maturidade e à felicidade, como posso acreditar que a do outro vai? (MSGS) 
Rogers (2001a) enfatiza a importância do desenvolvimento da congruência como atitude indispensável para se estabelecer uma relação de ajuda ao outro. Se a pessoa puder estar sensivelmente consciente de seus próprios sentimentos e aceitálos, é grande a possibilidade de poder vir a estabelecer uma relação de ajuda com outra pessoa. Para o autor, se há no sujeito o desejo de facilitar o desenvolvimento pessoal dos outros em relação com ele, é necessário desenvolver-se igualmente ressaltando que, embora isso seja muitas vezes penoso, é também fecundo.

Ainda em relação às reflexões sobre si, na reduzida amostragem foram encontrados dois registros de início de processos terapêuticos concomitantes ao curso da disciplina:

Um pensamento que passou várias vezes pela minha cabeça hoje foi a procura de um psicólogo ou psicóloga para começar a fazer terapia. Eu tinha discutido isso várias vezes com a família durante as minhas férias, mas agora eu senti que precisava criar coragem de pegar aquele passo e ir, pois eu acho importante e interessante a oportunidade de eu conhecer mais sobre mim mesmo. (DGS)

Mudanças significativas podem surgir em decorrência da criação de um espaço dialógico de aprendizagem onde os sujeitos podem ser quem são, sem defesas ou máscaras. A consideração incondicional, como atitude de aceitação e respeito a toda experiência subjetiva dos sujeitos implicados nesse processo, deve ser não apenas valorizada, mas construída e incentivada, pois a possibilidade de desenvolvimento está presente na situação relacional com o outro mais experiente que cria oportunidades de avanço tanto em direção ao desenvolvimento pessoal quanto profissional (Tacca, 2015).

Os processos de aprendizagem considerados significativos devem combinar aspectos cognitivos e afetivos-vivenciais (Rogers \& Rosenberg, 2005). Quando pensamos na formação de psicólogas(os) tal demanda é ainda mais evidente. Rogers (1983) defende que a formação de um terapeuta centrado na pessoa diz respeito ao desenvolvimento de uma postura de facilitador - o que inclui a compreensão empática, consideração positiva incondicional e congruência. Para que esse jeito de ser seja apreendido e desenvolvido, é indispensável que se vivencie uma relação onde a pessoa seja alvo do acolhimento e aceitação integrais de suas vivências e de suas características pessoais. Isso implica em uma abertura confiante à mudança e à autonomia com uma consciência de si rica e elevada que acaba por valorizar uma percepção de si e dos outros mais profunda e disponível no lugar de buscar o controle, inclusive terapêutico, sobre as pessoas.

\section{Desenvolvimento de habilidades interpessoais}

O desenvolvimento de habilidades interpessoais relacionadas à Abordagem Centrada na Pessoa é mencionado por nove estudantes em dezoito ocasiões. Foram encontrados vários relatos mencionando uma busca por agir de acordo com os preceitos da ACP em diferentes circunstâncias:

Consegui entender um pouco a angústia dele, mas haveria também a necessidade de ele se entender no contexto do relacionamento. É interessante que em muitas destas situações tenho buscado reconhecer as potencialidades das pessoas. Assim, poder vivenciar novamente a ACP só tem reforçado essa minha proposta. (LFMR)

Entre as reflexões encontramos também a valorização de práticas e posturas relacionadas à Abordagem Centrada na Pessoa:

Tenho cada vez mais vontade de que as pessoas sejam elas mesmas, autênticas e livres, quando estiverem do meu lado. (LM)

Me toquei das habilidades importantes que um psicólogo deve ter: a aceitação e a tolerância pelas pessoas que pensam diferente de mim, evitando conflitos, preconceitos e julgamentos. (DSG)

Vale destacar que, ao tentar exercer posturas relacionadas à ACP, muitas vezes estudantes relatavam dificuldades, levantando dúvidas acerca de suas habilidades

Atitudes facilitadoras: será que estou mesmo conseguindo criar para ela [mãe] momentos que possam facilitar seu desenvolvimento à superação? Pensando não só no caso dela, mas no geral, ainda sinto dúvidas de como nós terapeutas podemos despertar esse mecanismo de autorregulação, de equilíbrio. (LFMR)

Terapeutas centrados na pessoa são profissionais que devem dizer "sim" à pessoa que está se desenvolvendo constantemente, colocandose como um companheiro fiel e atento ao outro, partindo da premissa de que o centro de poder da tomada de decisões encontra-se na própria pessoa (Tassinari, 2016). Mais uma vez, o pensamento de Rogers (2001b) sobre a importância de o terapeuta experimentar em si mesmo o desenvolvimento da confiança nesse potencial interno evidenciase. Vivenciar uma relação onde pode-se conduzir suas escolhas e sentir-se aceito nelas, desenvolve, também, a habilidade de criar esse espaço onde o 
outro possa desenvolver-se de forma autônoma. Nos diários também foram identificadas situações de autorreflexão a partir dos temas trabalhados na disciplina, inclusive culminando na autorização para ser "si mesma(o)":

Também notei que, devido a uma sugestão da [apelido da professora], no começo do semestre, para tentarmos agir de forma mais compreensiva, porém sem deixar de ser congruente, eu realmente tentei e consegui fazer isso. Eu estou mais feliz com essa percepção, por sinal. Porque eu tinha esse sofrimento de me sentir na obrigação do controle, de dizer às pessoas o que fazer e de estar sempre certa. (BSG)

Os diários possibilitam que estudantes observem transformações em si, desenvolvendo a habilidade de se perceber e adquirindo confiança neste processo a partir de sua vivência pessoal. É como se o terapeuta acompanhasse confiantemente o cliente, muitas vezes amedrontado, na corrente do vir-a-ser, pois o próprio terapeuta já se deixou flutuar previamente nesta corrente de experiência ou de vida, percebendo-a como compensadora. Isso torna o psicólogo cada vez menos temeroso e é essa confiança que facilita ao cliente também embarcar em seu próprio processo de transformação pessoal. Sentir-se aceito pelo outro é um fator facilitador do processo de autoaceitação. Da mesma maneira, o processo de autoaceitação é também facilitador do desenvolvimento da capacidade de aceitar o outro da maneira que é. Dessa forma, em um ciclo que se retroalimenta, a pessoa torna-se mais capaz de ser congruente consigo e empática com o outro (Rogers, 2001a).

A compreensão de que há aprendizagem dessas habilidades de autocuidado, autoempatia, congruência, autoaceitação e autenticidade a partir da experienciação desse processo por estudantes de psicologia, coaduna com a perspectiva da educação e desenvolvimento de habilidades terapêuticas para a ACP. Quando uma pessoa se sente compreendida de maneira sensível e correta, sente-se também livre para expressar-se de maneira genuína, desenvolvendo um conjunto de atitudes promotoras de crescimento em relação a si mesma. A característica nãoavaliativa e aceitadora do clima empático capacita o sujeito a assumir uma atitude de estima e interesse por si mesmo. A maior autocompreensão e autoestima, por sua vez, mostram a essa pessoa aspectos da sua experiência que se tornam parte de um self com bases mais precisas, com maior congruência entre este self e suas vivências. Dessa forma, torna-se mais interessada e aceitadora, mais empática e compreensiva, real e congruente em suas atitudes com relação a si mesma e, posterior e consequentemente, com relação ao outro (Rogers \& Rosenberg, 2005).

\section{Relacão entre professora e estudantes}

Um ponto bastante interessante que emergiu nos diários de nove estudantes em quinze momentos foi uma relação próxima e afetuosa com a professora. A docente é sempre referida a partir de seu apelido e existe uma grande honestidade na relação com a mesma:

Cara [apelido da professora], não tive tempo de revisar. Você irá ler a autenticidade dos meus sentimentos e erros [carinha de risada]. (BSG)

[Apelido da professora], eu admito, escrevi tudo de última hora. (MSGS)

Há também um sentimento de sentir acolhimento da professora em direção a elas(es), fosse dentro ou fora da sala de aula:

Apesar da falta na aula, conversar contigo foi muito bom, ainda mais pelo cuidado que você tem conosco. Apesar de ter sido um pequeno equívoco [o motivo da falta dele na aula] foi legal perceber sua solidariedade. (LFMR)

Obrigada por fazer a diferença não só como professora no curso de Psicologia, mas como pessoa antes de tudo. (GCB)

A criação de um espaço dialógico em sala de aula entre docente e estudante e estudantes entre si favorece que questões pessoais emerjam sem medo de julgamentos ou reprovações (Tacca, 2015). É essa liberdade de expressar-se livremente, podendo ser quem de fato é, sem necessidade de máscaras ou disfarces, que possibilita ao sujeito acessar, rever e, então, mudar posturas pessoais. Ao realizarem registros pessoais em seus diários, estudantes têm a possibilidade de desenvolverem em si as habilidades de aceitação (de si e do outro) e de não julgamento e empatia, posturas importantes para a efetividade do psicólogo em sua atuação profissional.

Essa postura de autenticidade pode ser encorajada pela pessoa responsável pela facilitação quando assume-se o risco de se revelar verdadeiramente, relacionando-se com estudantes sem revestir-se de uma fachada. Ser genuíno nessa relação implica em experimentar os sentimentos que vivencia, tornandoos disponíveis à sua própria percepção, sendo capaz tanto de vivê-los quanto de comunicá-los se o desejar. Dessa forma, o encontro com estudantes torna-se direto e pessoal, chegando-se a uma base pessoa-apessoa, estando a figura docente inteiramente presente, de forma autêntica e não se negando. Essa atitude é também convidativa aos aprendizes para que se abram, também, à sua própria experiência e arrisquem-se a 
serem eles mesmos, experimentando e desenvolvendo a própria autenticidade (Rogers \& Rosenberg, 2005).

Éimportanteressaltar a relevância desses processos reflexivos em estudantes de psicologia e, especialmente, como uma relação dialógica facilitada pela postura de acolhimento docente, podendo favorecer a mudança a partir do diálogo genuíno, receptivo e caloroso. A essa perspectiva onde as alteridades são aceitas e cada sujeito pode ser visto e respeitado como único, protagonizando, assim, seu processo de desenvolvimento de maneira autônoma, pode-se relacionar o pensamento de Rogers (2001a). O ser humanoé dotado de potencial para crescer e se desenvolver. Esse potencial é inerente à pessoa, mas para que se manifeste é necessário que haja um clima interpessoal favorável a esse desenvolvimento, ou seja, o desenvolvimento acontece nas relações que o sujeito estabelece com o outro.

\section{Futuro enquanto profissional da psicologia}

O último item, indicado por seis estudantes em oito ocasiões diferentes são as preocupações ereflexões acerca do futuro profissional, não se sentindo aptos para exercerem a prática da clínica psicológica. São mencionados receios quanto a estarem aptas(os) para a profissão, valorização da mesma, autoafirmação enquanto futuras(os) psicólogos e o interesse em seguir a Abordagem Centrada na Pessoa.

Essa angústia é causada pela sensação de achar que nunca estarei realmente pronta para lidar, da forma necessária, com outra alma humana. É angustiante também saber as consequências que um erro que eu tiver, como profissional, pode impactar na vida da pessoa que eu atender. (TLB)

Falar sobre o CVV, sobre a atuação do psicoterapeuta diante de certos casos, nos faz refletir ainda mais sobre a nossa profissão e sobre quão grande é a nossa responsabilidade diante do outro. (GCB)

A consciência da responsabilidade da atuação do psicólogo evidencia-se nos relatos, fazendo emergir dualidades de sentimentos nos aprendizes: o interesse pelo que há de mais valoroso no outro e o receio de intervir erroneamente em seu processo. Em nossa organização social, é possível perceber que as relações são estruturadas, na maioria das vezes, de forma hierárquica, sem espaço para o desenvolvimento de empatia e compreensão, ou para assumir medos e inseguranças. A angústia descrita por estudantes em serem capazes de exercer uma postura empática e flexível na sua atuação, pode estar ligada a essa escassez de relações dialógicas que os possibilitassem posicionarem-se de maneira acolhedora e afetiva, confiando nessas atitudes como facilitadoras do processo de desenvolvimento humano (Rogers, 2001b).
Ressaltamos aqui, o valor formativo dessa percepção da própria angústia com relação a essa atuação profissional. A construção desse espaço de autorreflexão através da escrita dos diários oportunizou que esses estudantes entrassem em contato com sua insegurança e pudessem vir a trabalhá-las a partir do dar-se conta de si, que aconteceu porque existiu um espaço para olhar para si.

\section{Considerações Finais}

A partir das experiências vividas e refletidas por estudantes em seus diários, pode-se perceber que relações dialógicas facilitadoras do processo de aprendizagem e do desenvolvimento humano, quando presentes na educação formal, podem se tornar molas propulsoras tanto de uma aprendizagem significativa quanto do protagonismo dos sujeitos em seus processos de crescimento. Na formação de psicólogos, além de contribuírem com o crescimento pessoal de estudantes, podem também influenciar no desenvolvimento de competências profissionais importantes para a prática da psicologia, favorecendo a transformação em modos de subjetivação dos aprendizes, seu desenvolvimento pessoal, a apropriação e expansão de habilidades para o futuro exercício da profissão. Cabe, assim, ao quadro docente na formação, o compromisso de atuarem como agentes de transformação de realidades sociais e a missão de escutar e cuidar de seus aprendizes.

A escrita de um diário a partir da perspectiva da VS se mostrou pertinente, tendo em vista seu potencial de presentificar a intensidade vivida ao mesmo tempo em que garante a elaboração da mesma, colaborando para a consolidação de atitudes relacionadas à atividade do psicólogo centrado na pessoa (Vieira et al., 2018). Esta prática pedagógica tem a intenção de agregar mais sentido aos temas estudados, uma vez que busca proporcionar uma reflexão profunda e prolongada sobre os conteúdos e a relação de estudantes com os mesmos. Sugere-se mais estudos nos quais a formação de profissionais da psicologia seja permeada por espaços que promovam a reflexão de conteúdos pedagógicos e também de vivências pessoais e grupais, seja em estágios, disciplinas de diferentes eixos teóricos, espaços de pesquisa, entre outros.

Reconhecemos que a afinidade teórica da disciplina em questão com o instrumento utilizado, fomentou construções ricas e congruentes com o conteúdo trabalhado. No entanto acreditamos que esta prática pode também possibilitar aprendizados significativos mesmo que utilizada em disciplinas diferentes, uma vez que as condições para isso estão mais relacionadas à postura docente que ao instrumento em si. Acreditamos que a abertura do professor às vivências e feedbacks dos estudantes são precursores de uma educação autônoma e responsável, sendo o instrumento da VS um meio que facilita a construção dessa relação horizontalizada 
onde estudantes podem assumir o protagonismo de sua formação.

\section{Referências}

Amatuzzi, M. (1989). O Resgate da Fala Autêntica - Filosofia da Psicoterapia e da Educação. Papirus, São Paulo.

Amatuzzi, M. (2001). Por uma psicologia humana. Campinas: Alínea.

Bock, A. M. B. (2015). Perspectivas para a formação em psicologia. Psicologia Ensino \& Formação, 6(2), 114-122. Disponível em: http:/pepsic.bvsalud.org/pdf/pef/v6n2/v6n2a09.pdf

Dewey, J. (1933). How We Think: A Restatement of the Relation of Reflective Thinking to the Educative Process. Boston, MA: D.C. Heath \& Co Publishers. Disponível em: https://www.gutenberg.org/ ebooks/37423

Dourado, A. M., Quirino, C. A., Lima, M. B. A., \& Melo, S. M. V. (2016). Experiências de estudantes de psicologia em oficinas de desenvolvimento da escuta. Revista da Abordagem Gestáltica, 22(2), 209-218. Disponível em: http:// pepsic.bvsalud.org/scielo.php?script $=$ sci_arttext\&pid $=$ S1809-68672016000200013\&lng $=$ pt\&tlng $=p t$

Flôr, M. (2016). As Possibilidades de Aplicação da Abordagem Centrada na Pessoa. Em A. Barcellar (Org.), Psicologia Humanista na Prática Reflexões sobre a Abordagem Centrada na Pessoa volume 2 (pp. 88 - 118). Palhoça: Unisul

Heim, C. (2012). Tutorial facilitation in the humanities based on the tenets of Carl Rogers. Higher Education, 63, 289 - 298. Disponível em: http:// eprints.qut.edu.au/48358/2/48358.pdf

Freire, L. G. L., \& Duarte, A. M. (2016) Concepções de estudantes universitários brasileiros sobre os fatores e as funções da aprendizagem. Ensaio: aval. pol. públ. Educ., 24(91), 380-394. Disponível em: http://www.scielo.br/pdf/ensaio/v24n91/1809-4465-ensaio-24-91-0380.pdf

Moon, J. (2006). A Handbook of Reflective and Experiential Learning: Theory and Practice. London, RoutledgeFalmer. Disponível em: https:/epdf. tips/learning-journals-a-handbook-for-academics-students-and-professional-development.html

Norton, L. (2009). Action Research in Teaching and Learning: A practical guide to conducting pedagogical research in universities. Routledge: New York.

Raisanen, M., Postareff, L., \&Lindblom-Ylänne, S. (2016). University students' self- and co-regulation of learning and processes of understanding: A person-oriented approach. Learning and
Individual Differences, 47, 281-288. Disponível em: https://doi.org/10.1016/j.lindif.2016.01.006

Ressurreição, S. B., \& Sampaio, S. M. R. (2017). Transições e reconfigurações do self de jovens indígenas na experiência universitária. Psicologia Escolar e Educacional, 21(3), 495-504. Disponível em: https://dx.doi.org/10.1590/21753539201702131118

Rodgers, C. (2002). Defining Reflection: Another Look at John Dewey and Reflective Thinking. Teachers College Record, 104, 842-866. Disponível em: http://dx.doi.org/10.1111/14679620.00181

Rogers, C. (1983). Um jeito de ser. São Paulo: EPU.

Rogers, C. (2001a). Tornar-se Pessoa. 5a ed. São Paulo: Martins Fontes

Rogers, C. (2001b). Sobre o Poder Pessoal. $4^{\mathrm{a}}$ ed. São Paulo. Martins Fontes.

Rogers, C., \& Rosenberg, R. (2005). A Pessoa como Centro. São Paulo: EPU - Editora Pedagógica e Universitária Ltda.

Tacca, C. (2015). Possibilidades da Teoria Histórico-Cultural e da Subjetividade para Reflexões e Mudanças na Ação Pedagógica de Professores. InterMeio, 21(41), 213-226. Disponível em: http://seer.ufms.br/ojs/index.php/intm/article/ download/2338/1422.

Tambara, N., \& Freire, E. (2007). Teoria Centrada no Cliente: Teoria e Prática: Um caminho sem volta. Porto Alegre: Delphos.

Tassinari, M. (2016). Os Desafios do Psicólogo/Praticante na Abordagem Centrada na Pessoa. Em A. Bacellar (Org.), Psicologia Humanista na Prática - Reflexões sobre a Abordagem Centrada na Pessoa volume 2 (pp.76-87). Palhoça: Unisul

Vieira, E. M., Bezerra, E. do N., Pinheiro, F. P., \& Branco, P. C. C. (2018). Versão de sentido na supervisão clínica centrada na pessoa: alteridade, presença e relação terapêutica. Revista Psicologia e Saúde, 10(1), 63-76. Disponível em: https://dx.doi.org/10.20435/pssa.v9i1.375

Juliana Crespo Lopes (https://orcid.org/00000003-4344-208X). Psicóloga (UFSC), Pedagoga (UNIRIO), Especialista em Psicopedagogia Clínica e Institucional (UnB). Mestra e Doutora na área de Desenvolvimento Humano e Educação (PGPDS/ 
UnB). Pesquisadora de Pós Doutorado na Karlova Univerzita (Charles University) em Praga, República Tcheca. Email: juliana.jcl@gmail.com

Francielly de Oliveira Müller Lima (https:// orcid.org/0000-0002-8338-6759). Professora e Supervisora de Estágio no Curso de Psicologia do Centro Universitário de Brasília (UniCEUB). Coordenadora do curso de Pós-Graduação em Psicologia Humanista - ACP (Unepos). Mestre em Processo de Desenvolvimento Humano e Saúde pela Universidade de Brasília, Especialista em Psicoterapia Existencial Fenomenológica / Abordagem Centrada na Pessoa pela Universidade FUMEC. Email: franciellymuller@gmail.com

Sandra Ferraz de Castillo Dourado Freire (Orcid https://orcid.org/0000-0002-6817-6358). Doutora em Processos de Desenvolvimento Humano e Saúde (Universidade de Brasília) e Mestre em Educação (Michigan State University, EUA). Docente na Faculdade de Educação da Universidade de Brasília.
Coordena o Laboratório de Práticas Dialógicas em Educação - Diálogo. Email: sandra.ferraz@gmail.com

Lúcia Helena Cavasin Zabotto Pulino (Orcid https://orcid.org/0000-0002-4701-2872). Professora Associada da Universidade de Brasília (PEDIP/UnB), Pesquisadora dos Programas de PósGraduação em Psicologia do Desenvolvimento e Escolar (PPGDE) e Direitos Humanos e Cidadania (PPGDH-CEAM/UnB). Psicóloga, Mestra em Lógica e Filosofia da Ciência e Doutora em Filosofia (UNICAMP), com Pós-Doutorados em Paris VIII, La Serena (Chile), UERJ e Universidad de Barcelona. Email: luciahelenaczp@gmail.com

Recebido em 22.10.2019

Primeira Decisão Editorial em 15.04.2020

Aceito em 22.04.2020

${ }^{1}$ Traremos ao longo do artigo recortes de diários de aprendizagem dos estudantes, identificando-os pelas iniciais. 